\title{
Research on Computer Information Processing Technology in Mass Data Era
}

\author{
Zhang Zhiqiang \\ Xi'an International University, Xi’an, Shaanxi, 710077
}

Keywords: mass data; computer; information processing

\begin{abstract}
To the credit of computer information processing, Internet has been developing rapidly worldwide. The internet has brought many a change to people's work and daily life. Under the background of the new era, the current information processing technology will encounter a lot of pressure and challenges. Faced with such opportunities and challenges, it is the only way for the technology to find its ground in the wave, that is to enhance computer technology continuously, to deepen data processing, and to perfect network security. This paper mainly analyses the direction of computer information processing technology and the strategy to survive in the new era.
\end{abstract}

\section{Introduction}

The popularization of computer and network technology is now booming like a raging fire. With the help of network, information sharing has come true. Computer information processing is the most common and advanced technology nowadays. Plenty of information can be seen or heard in people's work and daily life by surfing the Internet. This explosion of information resources has brought heavy pressure to the computer. The computer is the most fundamental and at the same time the most important part as to information processing technology. Under the environment of mass data era, problems to be solved are how to grasp the current direction of the development of information processing technology, and how to improve and innovate itself on the current basis.

\section{Mass Data and the Application of Computer Information Processing Technology}

"Mass data", as the name suggests, is the index of huge amount of data, which is only the superficial meaning. The deep understanding of "Mass data" also includes the gradual complexity, diversity and repetition of information. ${ }^{[1]}$ With today's development of virtual network globally, the birth of "mass data era" is historically inevitable. Compared to the traditional way of calculation, "mass data" bears the advantages of low cost, high efficiency and etc. Although "mass data" means a huge amount and variety of information, "mass data" technology, with the help of computer technology, is able store the information for later use. Network technology spares the reliability of solid media such as mobile hard disks, U disks, or memory cards when people store information. Now there are new options like 360 SkyDrive, Baidu Cloud and etc. Network has further changed people's way of life and benefits "mass data” technology towards a higher level.

The applied computer information processing technology is a basic means to conduct daily work in various fields of modern society. There are many applications of computer information processing technology, such as data transmission, data storage, information analysis, which are important means of information processing, and makes it much more convenient for information management, and improves efficiency. No matter how many kinds of information processing technology there are, the computer is always the core technology, hence the key status of computer technology. The applied computer information processing technology consists of three elements, namely software, hardware and people. Only when the three elements are effectively combined, will it be able to carry out daily work efficiently. 


\section{Means of Applied Computer Information Processing in Mass Data Internet Technology Era}

Information collecting, the basis of information analysis, information storage, transmission and other related technologies, is the key part for information processing and the prerequisite for other technologies' functioning and actualizing. Information collecting is the pre-condition for information's reorganization and transmission. In order to collect information, a huge amount of data monitoring work is needed. Then store the collected information into a database for later convenience. Therefore, information processing is to reorganize and process the collected information by information processing system for people's searching aimed information in the future. ${ }^{[2]}$

As for information storage and backup, it refers to saving information after being processed by storage media of solid disk or network, and then building a database for future need. Database is of great importance in the mass data era when information is massive and updates rapidly. Such database, on the one hand, saves a large amount of manpower and material resources, and on the other hand, brings about great convenience for people's daily work and life, hence of the improved efficiency.

In "mass data" era, information collecting, processing, transmission and reorganization are conducted by computers and network, bringing significance to computer information processing technology. Security technology ensures the normal operation of information processing. What security technology faces is not just a separate data system. Measures should be taken to prevent and control possible risks work from all aspects. To guarantee the information processing conducts smoothly and effectively, several measures are to be taken as follows: Firstly, establish a thorough information security system. Secondly, innovate the technology for network security the continuously to handle endless network security problems emerging in the mass data era. Finally, increase the intensity of information monitoring so that the system loopholes can be found and repaired timely.

The transmission of information has strengthened communication between people in the new era, making it real to know the world's affairs well without going out. Advanced information transmission technology is needed when people chat over WeChat, MSN, or QQ, or when posting articles or pictures on Microblog, Q-zone, or other websites. The transmission of information has an extensive impact in everyday life. So it is with many work fields, such as aerospace engineering, electric power system, where the advanced technology of information transmission plays a vital role. The technology narrows the distance between people and people, people and science, as well as the distance between the different fields.

\section{Actual Situation of Applied Computer Information Processing Technology at the Current Stage}

Under the background of mass data era, applied computer information processing technology is now faced with both challenges and opportunities.

\subsection{Industrial value based on data mining and application}

Data mining refers to finding out the hidden rules of data through the analysis of a large amount of data. More profit will be made by applying the rules in industry operation. Information collecting's value is limited and a rather low level of obtaining data, which is to gather and reorganize every single bit of data, and then add it to a database. Only when the hidden rules among massive data are revealed, will it be possible to bring more profit in industries by applying the rules of data.

\subsection{Bring more advanced technologies like networking and cloud computation}

Networking is a combination of the essence of network, computer and many other advanced technologies. As a representative of high and new technologies, networking has been applied to 
many engineering fields and many new industries, like electronic wallets and public transportation card, has derived from it under the circumstances of mass data era. ${ }^{[3]}$ Under new situations and circumstances, cloud services stand for the trend of the innovation of new technology. Major domestic major technology companies have all joined the stream of cloud services, such as 360 SkyDrive, Baidu Cloud and etc. And people's way of living is gradually changed by these new technology products.

\subsection{Promote the improvement and development of network information security system}

Networking and cloud computing, based on the most advanced science and technology, are representatives of network technology innovation. A corresponding security system for maintenance and protection is inevitably needed in the process of these new technologies' development. New high-tech products are made out of the most advanced technology. Therefore, the current network security system will not be able to solve the new upcoming problems, hence of higher requirement to improve the network security system. At the same time, cloud computing and networking can provide the innovation of network security technology and thereby promote the overall development of network security system.

(1) Higher reliability on network security environment

Mass data era is an era based on computer and network technologies, hence of the importance of network security environment. When shopping on-line, one must always pay attention to network security to avoid possible financial loss. And network server companies can track users' surfing log according he magnetic stripe information online, which brings hidden trouble to the security of the network. Therefore, the government must consummate related laws and regulations timely to provide legal protection for the people.

(2) Higher requirements for the value of data

Mass data era is an era of data explosion. How to obtain valuable information in the sea of data, is an urgent problem for all fields of industry. At the present stage, it brings obstacles to data analysis that the huge number of data, and the work to distinguish the data between true and false. the greater the data analysis work which makes analysis difficult, which highlighted the significance of selecting valuable information.

(3) Higher demand for skilled technicians

In the mass data era when network and computer technology are highly advanced, skilled technicians are needed in all fields of industry. People who master professional techniques are scarce resources. However, there is a paradox between the rapid development of technology and the lag of training skilled technicians. This brings tremendous challenges to the whole society.

\section{Outlook of Computer Information Processing Technology}

Currently, the pace of cloud services has already set out. With rapid development of the computer and network technology, cloud computing will develop quickly and consummate itself in the future. Cloud computing brings much more convenience to people's work and daily life. Cloud computing will inevitably be the direction of computer and network technology.

There will be higher requirements for network security to meet with the development of computer network technology. In order to meet the continuous development of new science and technology, and safeguard all fields of the society, network security issue will be a focus. In the new resource sharing era, the use of computer and network is constantly increasing. Therefore, it is a must to enhance network security timely in order that people's daily life and work can be carried out in an orderly manner.

\section{Conclusion}

With the development of computer and network technology, the mass data era has come. In this global mass data era, applied computer information processing technology is faced with severe challenges and infinite opportunities. Mass data is a double-edged sword for information processing. 
It is the priority to find out a solution with which people can use the "sword" correctly and effectively to maximize benefit and minimize detriment. It is the present first issue towards cloud computing. The direction of applied computer information processing technology is cloud computation and to strengthen network security. Only in a safe environment, can the technology bring prosperity of industries.

\section{Acknowledgements}

Pro: Project: Xi'an social science planning fund project, the association analysis of data mining based on the data mining technology, the project number is 16IN08

\section{References}

[1] James Shaoqiang, Analysis on computer information processing technology based on the mass data era [J]. Network Security Technology and Application, 2014, 08: 49-50.

[2] Zhang Ping. Application of computer information processing technology in the mass data era[J]. Information and Computer (theoretical Edition), 2016,03: 15-16.

[3] Li Fuquan. The analysis on computer information processing technology in the mass data era[J]. China New Technology and New Products, 2016, 11:32-33. 